\title{
Long-Term Facial Nerve Outcomes after Microsurgical Resection of Vestibular Schwannomas in Patients with Preoperative Facial Nerve Palsy
}

\author{
Michael A. Mooney ${ }^{1} \quad$ Benjamin Hendricks ${ }^{1} \quad$ Christina E. Sarris ${ }^{1}$ Robert F. Spetzler ${ }^{1} \quad$ Kaith K. Almefty $^{1}$ \\ Randall W. Porter ${ }^{1}$ \\ ${ }^{1}$ Department of Neurosurgery, Barrow Neurological Institute, \\ St. Joseph's Hospital and Medical Center, Phoenix, \\ Arizona, United States \\ Address for correspondence Kaith K. Almefty, MD, Department of \\ Neurosurgery, Barrow Neurological Institute, St. Joseph's Hospital \\ and Medical Center, 350 West Thomas Road, Phoenix, AZ 85013, \\ J Neurol Surg B 2018;79:309-313. \\ United States (e-mail: Neuropub@barrowneuro.org).
}

\begin{abstract}
\section{Keywords}

- acoustic neuroma

- facial nerve

- facial palsy

- microsurgery

- vestibular schwannoma

Objectives This study aimed at evaluating facial nerve outcomes in vestibular schwannoma patients presenting with preoperative facial nerve palsy.

Design A retrospective review.

Setting Single-institution cohort.

Participants Overall, 368 consecutive patients underwent vestibular schwannoma resection. Patients with prior microsurgery or radiosurgery were excluded.

Main Outcome Measures Incidence, House-Brackmann grade.

Results Of 368 patients, 9 had confirmed preoperative facial nerve dysfunction not caused by prior treatment, for an estimated incidence of $2.4 \%$. Seven of these nine patients had Koos grade 4 tumors. Mean tumor diameter was $3.0 \mathrm{~cm}$ (range: 2.1$4.4 \mathrm{~cm}$ ), and seven of nine tumors were subtotally resected. All nine patients were followed up clinically for $\geq 6$ months. Of the six patients with a preoperative HouseBrackmann grade of II, two improved to grade I, three were stable, and one patient worsened to grade III. Of the three patients with grade III or worse, all remained stable at last follow-up.

Conclusions Preoperative facial nerve palsy is rare in patients with vestibular schwannoma; it tends to occur in patients with relatively large lesions. Detailed long-term outcomes of facial nerve function after microsurgical resection for these patients have not been reported previously. We followed nine patients and found that eight $(89 \%)$ of the nine patients had either stable or improved facial nerve outcomes after treatment. Management strategies varied for these patients, including rates of subtotal versus gross-total resection and the use of stereotactic radiosurgery in patients with residual tumor. These results can be used to help counsel patients preoperatively on expected outcomes of facial nerve function after treatment.
\end{abstract}

(c) 2018 Georg Thieme Verlag KG Stuttgart · New York
DOI https://doi.org/

10.1055/s-0037-1607320. ISSN 2193-6331. 


\section{Introduction}

Facial nerve palsy is a rare presenting symptom of vestibular schwannoma that occurs in 2 to $6 \%$ of patients. ${ }^{1-6}$ Facial nerve palsy tends to occur in patients with larger compressive tumors in a more medial ("cisternal") location, ${ }^{7-11}$ and facial nerve function can therefore benefit from vestibular schwannoma resection and decompression of the nerve. Unfortunately, the same factors that compromise the nerve initially (i.e., large tumor volume and facial nerve compression) also increase the risk for facial nerve palsy after microsurgical resection. 1,3,7,12-20 Facial nerve outcomes in patients presenting with preoperative palsy have not been well established. This cohort of patients is rarely distinguished in surgical series, and facial nerve outcomes are often omitted or grouped with those of patients who have undergone prior treatment., $3,7,10,12-15,17-19,21-23$ To our knowledge, no study outlining long-term facial nerve outcomes in these patients has been reported to date in the neurosurgery literature.

This study was designed to assess long-term facial nerve outcomes in patients with a preoperative facial palsy without prior treatment who underwent microsurgical vestibular schwannoma resection.

\section{Methods}

A retrospective review was performed of all patients with vestibular schwannoma resections performed at Barrow Neurological Institute from January 1, 2008 to August 31, 2016. This review identified 368 patients, 17 of whom had a preoperative House-Brackmann grade of II or greater. Eight of the 17 patients who had a history of operative resection of the vestibular schwannoma at another facility were excluded, leaving 9 patients (2.4\%) with "spontaneous" preoperative facial palsy for review.

A detailed review was conducted of all the clinical and radiographic records of these nine patients. The data reviewed included patient demographics, preoperative House-Brackmann grade, surgical approach, the extent of resection, and postoperative treatment and outcomes. Preoperative imaging studies and radiology reports were examined to determine the maximum tumor diameter and Koos grade. The most recent clinical follow-up was reviewed to determine the final HouseBrackmann grade. Vestibular schwannomas were distinguished from facial nerve schwannomas on the basis of clinical records, neuroimaging studies, intraoperative inspection, and intraoperative facial nerve monitoring results. We distinguished the lesions in this series from facial nerve schwannomas by the lack of intraoperative neurostimulation of the capsule of the tumor. Detailed intraoperative facial nerve monitoring data were not available for retrospective review.

IBM SPSS Statistics for Windows, version 23.0, (IBM Corp.) was used for all data analysis. Descriptive statistics were used to analyze patient demographics, presenting symptoms, perioperative complications, and tumor characteristics. Continuous variables were described as means, medians, and interquartile ranges, as appropriate, and categorical variables were presented as frequencies. This review was approved by the Institutional Review Board of St. Joseph's Hospital and Medical Center (PHX-16-0218-71-12).

\section{Results}

Patient demographics, preoperative characteristics, and postoperative outcomes are summarized in - Table 1. Seven of the nine patients in this series had Koos grade 4 tumors, with a mean tumor diameter of $3.0 \mathrm{~cm}$ (range: $2.1-4.4 \mathrm{~cm}$ ). Most of the tumors had a cystic component (56\%, 5/9). The duration of preoperative facial palsy was known for eight of the nine patients (mean: 11.9 months, median: 7.0 months, range: 2-36). No patient in the series had previously undergone microsurgery or radiotherapy.

House-Brackmann facial palsy grading was tracked during the preoperative and perioperative courses of the nine patients and their long-term follow-up (-Fig. 1, - Table 2). Of the nine patients, six had a preoperative grade of II and one each had grades of III, III, and V. Of the six patients with grade II, one patient improved postoperatively to grade I,

Table 1 Patient and tumor characteristics

\begin{tabular}{|l|l|l|l|l|l|l|l|l|l|}
\hline $\begin{array}{l}\text { Patient } \\
\text { no. }\end{array}$ & Sex & $\begin{array}{l}\text { Age } \\
\text { (y) }\end{array}$ & $\begin{array}{l}\text { Koos } \\
\text { grade }\end{array}$ & $\begin{array}{l}\text { Largest tumor } \\
\text { dimension } \\
(\mathbf{c m})\end{array}$ & $\begin{array}{l}\text { Cystic } \\
\text { component }\end{array}$ & $\begin{array}{l}\text { Tumor } \\
\text { location }\end{array}$ & $\begin{array}{l}\text { Surgical } \\
\text { approach }\end{array}$ & $\begin{array}{l}\text { Postoperative } \\
\text { SRS performed }\end{array}$ & $\begin{array}{l}\text { Preoperative } \\
\text { duration of } \\
\text { palsy (wk) }\end{array}$ \\
\hline 1 & F & 51 & 4 & 3.1 & No & Lateral & RS & Yes & 6 \\
\hline 2 & M & 33 & 4 & 4.4 & Present & Lateral & TL & Yes & 12 \\
\hline 3 & M & 49 & 3 & 3.0 & Present & Lateral & RS & No & 5 \\
\hline 4 & F & 63 & 3 & 2.1 & Present & Lateral & TL & Yes & 36 \\
\hline 5 & M & 53 & 4 & 2.5 & No & Lateral & TL & No & 8 \\
\hline 6 & M & 38 & 4 & 3.3 & Present & Medial & TL & Yes & 24 \\
\hline 7 & F & 68 & 4 & 2.4 & Present & Lateral & RS & No & 2 \\
\hline 8 & F & 47 & 4 & 4.1 & No & Lateral & TL & No & NS \\
\hline 9 & F & 56 & 4 & 2.1 & No & Medial & RS & No & 2 \\
\hline
\end{tabular}

Abbreviations: F, female; HB, House-Brackmann; M, male; NS, not specified; RS, retrosigmoid; SRS, stereotactic radiosurgery; TL, translabyrinthine. 


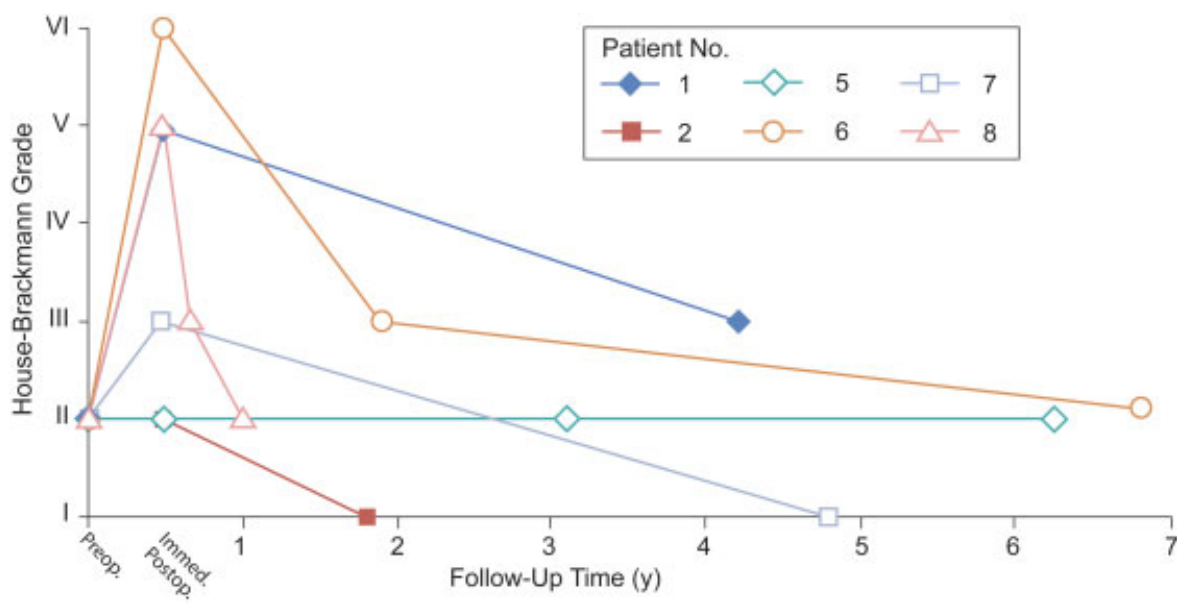

Fig. 1 Facial nerve outcomes for six patients with House-Brackmann grade II. Preoperative, immediate postoperative, and long-term facial nerve outcomes are plotted for six patients who had preoperative House-Brackmann grade II at presentation. The remaining three patients (patients 3, 4, and 9; data not shown) had stable preoperative and long-term outcomes of facial nerve function (House-Brackmann grade III, V, and III, respectively). (Used with permission from Barrow Neurological Institute, Phoenix, Arizona, United States.)

Table 2 Postoperative outcomes

\begin{tabular}{|l|l|l|l|l|l|}
\hline $\begin{array}{l}\text { Patient } \\
\text { no. }\end{array}$ & $\begin{array}{l}\text { Extent of } \\
\text { resection }\end{array}$ & $\begin{array}{l}\text { Follow-up } \\
\text { duration (y) }\end{array}$ & $\begin{array}{l}\text { Preoperative } \\
\text { HB grade }\end{array}$ & $\begin{array}{l}\text { Postoperative } \\
\text { HB grade }\end{array}$ & $\begin{array}{l}\text { Current } \\
\text { HB grade }\end{array}$ \\
\hline 1 & STR & 4.2 & 2 & 5 & 3 \\
\hline 2 & STR & 1.8 & 2 & 2 & 1 \\
\hline 3 & GTR & 3.9 & 3 & 3 & 5 \\
\hline 4 & STR & 1.1 & 5 & 2 & 3 \\
\hline 5 & GTR & 6.3 & 2 & 6 & 5 \\
\hline 6 & STR & 6.8 & 2 & 3 & 2 \\
\hline 7 & STR & 4.8 & 2 & 5 & 1 \\
\hline 8 & STR & 1.0 & 3 & 5 & 2 \\
\hline 9 & STR & 0.5 & 2 & 3 \\
\hline
\end{tabular}

Abbreviations: GTR, gross-total resection; HB, House-Brackmann; STR, subtotal resection.

three patients were stable, and one patient worsened to grade III. The three patients who had preoperative grades of III, III, and V were stable at long-term follow-up of $0.5,1.1$, and 3.9 years, respectively. For these patients, the preoperative House-Brackmann grade appeared to be a better predictor of long-term outcome than the postoperative grade. The one patient with grade $\mathrm{V}$ facial palsy after surgery underwent placement of a gold weight in the right eyelid to assist with eye closure and had good results. No other cases of plastic surgery intervention or facial reanimation have yet been attempted in this group of patients.

\section{Discussion}

Numerous studies have evaluated preoperative, intraoperative, and postoperative predictors of long-term facial nerve outcomes. Factors consistently cited for predicting worse postoperative facial nerve outcomes include large tumor size, medial (cisternal) location, intraoperative nerve manip- ulation, neurophysiologic monitoring feedback, immediate postoperative House-Brackmann grade, and the presence of preoperative facial nerve palsy. ${ }^{1,2,7,11-16,20}$ Unfortunately, although preoperative palsy is often recognized in case series, facial palsy secondary to prior treatment (microsurgery or radiosurgery) is usually included in this category. Patients with palsy resulting from prior treatment represent an inherently different group than those with spontaneous facial palsy resulting from the vestibular schwannoma itself, and the outcomes of these two groups cannot be compared. Furthermore, studies that describe facial nerve outcomes often exclude patients with preoperative palsy from any cause, and little information exists on the long-term facial nerve outcomes of these patients. ${ }^{2-5,10,13-19,21-24}$

Postoperative recovery of facial nerve function is variable, with improvement over the course of weeks in some patients and the course of years in others. ${ }^{25}$ This fact has made facial nerve function the focus of many studies; however, clinical characteristics and prognostic factors continue to be defined. 
Recovery of nerve function depends on the recovery of axonal stretch injury, strengthening of remaining motor synapses at the neuromuscular junction, and even cortical reorganization and sensorimotor reintegration processes. ${ }^{16,25,26}$ It is accepted that the best recovery of facial nerve function for a postoperative facial nerve palsy occurs within the first 6 to 12 months, ${ }^{18,22,25}$ and after 1 year, nerve grafting techniques should be considered to offer patients with residual dysfunction the best chance of recovery. Notably, current electrophysiological monitoring capabilities fail to predict which patients will be left with "poor" facial function after surgery (HouseBrackmann grade IV or worse), which prohibits the use of these tools for intraoperative decision-making regarding neural grafting techniques. ${ }^{2,27}$

Minimal data exist regarding the timeline of recovery for patients with preoperative palsy, and the prognosis of facial nerve function in these patients is unknown. An early report by Neely and Neblett ${ }^{6}$ in 1983 described three patients with preoperative facial nerve palsy. All three of these patients with preoperative palsy had House-Brackmann grade VI facial nerve function postoperatively. However, this finding is likely due to the historical nature of this study and may not represent outcomes in the modern era of advanced microsurgical resection techniques. A later report by Inamasu et al. $^{9}$ in 2000 described two patients with preoperative House-Brackmann grade II facial palsy, both of whom remained stable at 6-month follow-up. No further clinical follow-up after 6 months was reported.

In our experience, patients with preoperative facial nerve palsy secondary to tumor mass effect may have satisfactory outcomes after resection of the vestibular schwannoma and decompression of the facial nerve, despite the added technical challenge of a compromised facial nerve in these cases. Indeed, in our small series, $89 \%(n=8)$ of the nine patients had stable to improved facial nerve outcomes after surgery, with two patients improving from House-Brackmann grade II preoperatively to House-Brackmann grade I. Most of the patients remained at their preoperative House-Brackmann grade during long-term follow-up, even if a postoperative decline in facial function was initially encountered. These findings must be interpreted in the context of heterogeneous treatment paradigms in this study; however, they suggest that preoperative facial nerve status may be more important for determining long-term outcome than immediate postoperative House-Brackmann grade.

Imaging characteristics and surgical goals must be carefully considered in these patients, and it is noteworthy that in this series the tumors were relatively large (mean: $2.9 \mathrm{~cm}$ ), often cystic, and that the gross-total resection rate was relatively low (22\%; 2 of 9 ). A review of the nine cases in this series suggests that the low gross-total resection rate was due to an intraoperative decision to leave residual tumor either because of difficulty identifying the facial nerve or because of dense tumor adherence to the facial nerve. However, in two cases, gross-total resection was achieved with stable facial nerve outcomes. On the basis of these findings, we recommend that an attempt at gross-total resection should be pursued, but only in a prudent manner, with an acceptance of residual tumor in cases in which the tumor cannot be safely dissected from the facial nerve. These are difficult decisions that must be made intraoperatively by experienced surgeons; however, even with subtotal resection, good decompression of the facial nerve and surrounding structures can be achieved. Our series shows that this strategy is worthwhile, since most of the nine patients had stable to improved facial function after surgery, and since no patient has required further treatment with repeat surgical resection to date. Of note, four of the nine patients underwent postoperative radiosurgery treatment, and we were unable to distinguish any negative effect from radiosurgery on facial nerve outcomes for these patients. Patients with subtotal resection must be followed over time, and further treatment in these patients would come with a separate risk profile for facial nerve outcomes.

This study is the first to define and report long-term outcomes for patients with preoperative facial nerve palsy; however, it does have several limitations. First, the study is retrospective in nature, and data available for review are limited to what is recorded in each patient's medical record, including physician-documented House-Brackmann grades at clinical follow-up visits. Second, two patients had only 6 to 12 months of follow-up at the time of this analysis, and further improvement of their facial function over a longer period cannot be ruled out. Third, it can be difficult to distinguish large vestibular schwannomas causing mass effect on the facial nerve from a true facial nerve schwannoma. We distinguished patients with vestibular schwannoma in this series from patients with facial nerve schwannoma on the basis of clinical presentation, imaging findings, intraoperative inspection, and intraoperative neuromonitoring feedback; however, the large size of these tumors might obscure their true nerve origin. Finally, treatment strategies were heterogeneous in this study, including a high rate of subtotal resection and subsequent radiosurgery treatment in four patients. Thus, we are unable to make any conclusions about specific treatment strategies to achieve the best facial nerve outcomes in this small cohort, and future studies are needed to document the best strategies for these unique patients better.

\section{Conclusions}

Understanding the prognosis of preoperative facial nerve palsy is important when counseling patients before vestibular schwannoma surgery. Good long-term outcomes for facial nerve function can be achieved in these patients despite the added technical difficulty related to tumor size and facial nerve compression, as shown by the fact that eight of these nine patients had stable or improved facial nerve outcomes after surgery. Rates of gross-total resection were relatively low in these patients because of the difficulty in identifying the facial nerve intraoperatively and because of tumor adherence; these outcomes can be anticipated and shared with patients before surgery. The future recording and reporting of facial nerve outcomes in patients with vestibular schwannomas as a distinct group would help to improve long-term follow-up data and guide future treatment strategies. 


\section{Acknowledgments}

The authors thank the staff of Neuroscience Publications at Barrow Neurological Institute for assistance with article preparation.

\section{References}

1 Rinaldi V, Casale M, Bressi F, et al. Facial nerve outcome after vestibular schwannoma surgery: our experience. J Neurol Surg B Skull Base 2012;73(01):21-27

2 Schmitt WR, Daube JR, Carlson ML, et al. Use of supramaximal stimulation to predict facial nerve outcomes following vestibular schwannoma microsurgery: results from a decade of experience. J Neurosurg 2013;118(01):206-212

3 Falcioni M, Fois P, Taibah A, Sanna M. Facial nerve function after vestibular schwannoma surgery. J Neurosurg 2011;115(04): 820-826

4 Samii M, Gerganov V, Samii A. Improved preservation of hearing and facial nerve function in vestibular schwannoma surgery via the retrosigmoid approach in a series of 200 patients. J Neurosurg 2006;105(04):527-535

5 Matthies C, Samii M. Management of 1000 vestibular schwannomas (acoustic neuromas): clinical presentation. Neurosurgery 1997;40(01):1-9, discussion 9-10

6 Neely JG, Neblett CR. Differential facial nerve function in tumors of the internal auditory meatus. Ann Otol Rhinol Laryngol 1983; 92(1 Pt 1):39-41

7 Dunn IF, Bi WL, Erkmen K, et al. Medial acoustic neuromas: clinical and surgical implications. J Neurosurg 2014;120(05):1095-1104

8 Kurokawa Y, Uede T, Hashi K. Factors influencing the long-term function of the facial nerve following removal of acoustic neurinomas [in Japanese]. No Shinkei Geka 1997;25(03):225-230

9 Inamasu J, Shiobara R, Kagami H, Sato S, Kawase T, Kanzaki J. Medial (intra-cisternal) acoustic neuromas. Acta Otolaryngol 2000;120(05):623-626

10 Anderson DE, Leonetti J, Wind JJ, Cribari D, Fahey K. Resection of large vestibular schwannomas: facial nerve preservation in the context of surgical approach and patient-assessed outcome. J Neurosurg 2005;102(04):643-649

11 Tos M, Youssef M, Thomsen J, Turgut S. Causes of facial nerve paresis after translabyrinthine surgery for acoustic neuroma. Ann Otol Rhinol Laryngol 1992;101(10):821-826

12 Bloch O, Sughrue ME, Kaur R, et al. Factors associated with preservation of facial nerve function after surgical resection of vestibular schwannoma. J Neurooncol 2011;102(02):281-286
13 Darrouzet V, Martel J, Enée V, Bébéar JP, Guérin J. Vestibular schwannoma surgery outcomes: our multidisciplinary experience in 400 cases over 17 years. Laryngoscope 2004;114(04):681-688

14 Brackmann DE, Cullen RD, Fisher LM. Facial nerve function after translabyrinthine vestibular schwannoma surgery. Otolaryngol Head Neck Surg 2007;136(05):773-777

15 Gormley WB, Sekhar LN, Wright DC, Kamerer D, Schessel D. Acoustic neuromas: results of current surgical management. Neurosurgery 1997;41(01):50-58, discussion 58-60

16 Sampath P, Holliday MJ, Brem H, Niparko JK, Long DM. Facial nerve injury in acoustic neuroma (vestibular schwannoma) surgery: etiology and prevention. J Neurosurg 1997;87(01):60-66

17 Esses BA, LaRouere MJ, Graham MD. Facial nerve outcome in acoustic tumor surgery. Am J Otol 1994;15(06):810-812

18 Fenton JE, Chin RY, Fagan PA, Sterkers O, Sterkers JM. Predictive factors of long-term facial nerve function after vestibular schwannoma surgery. Otol Neurotol 2002;23(03):388-392

19 Jacob A, Robinson LL Jr, Bortman JS, Yu L, Dodson EE, Welling DB. Nerve of origin, tumor size, hearing preservation, and facial nerve outcomes in 359 vestibular schwannoma resections at a tertiary care academic center. Laryngoscope 2007;117(12):2087-2092

20 Veronezi RJ, Fernandes YB, Borges G, Ramina R. Long-term facial nerve clinical evaluation following vestibular schwannoma surgery. Arq Neuropsiquiatr 2008;66(2A):194-198

21 Nonaka Y, Fukushima T, Watanabe K, et al. Contemporary surgical management of vestibular schwannomas: analysis of complications and lessons learned over the past decade. Neurosurgery 2013;72(2, Suppl Operative):ons103-ons115, discussion ons115

22 Hardy DG, Macfarlane R, Baguley D, Moffat DA. Surgery for acoustic neurinoma. An analysis of 100 translabyrinthine operations. J Neurosurg 1989;71(06):799-804

23 Arriaga MA, Luxford WM, Atkins JS Jr, Kwartler JA. Predicting long-term facial nerve outcome after acoustic neuroma surgery. Otolaryngol Head Neck Surg 1993;108(03):220-224

24 Sterkers JM, Morrison GA, Sterkers O, El-Dine MM. Preservation of facial, cochlear, and other nerve functions in acoustic neuroma treatment. Otolaryngol Head Neck Surg 1994;110(02):146-155

25 Rudman KL, Rhee JS. Habilitation of facial nerve dysfunction after resection of a vestibular schwannoma. Otolaryngol Clin North Am 2012;45(02):513-530, xi

26 Xiao FL, Gao PY, Sui BB, et al. Time-course of changes in activation among facial nerve injury: a functional imaging study. Medicine (Baltimore) 2015;94(43):e1582

27 Carlson ML, Van Abel KM, Schmitt WR, Driscoll CL, Neff BA, Link MJ. The anatomically intact but electrically unresponsive facial nerve in vestibular schwannoma surgery. Neurosurgery 2012;71 (06):1125-1130, discussion 1130 